\title{
Two new brachypterous species of Heterospilus Haliday (Hymenoptera, Braconidae, Doryctinae) from the Nearctic Region
}

\author{
Robert R. Kula \\ Systematic Entomology Laboratory, Plant Sciences Institute, Agricultural Research Service, U.S. Department of \\ Agriculture, clo National Museum of Natural History, Smithsonian Institution, P.O. Box 37012, MRC 168, \\ Washington, DC 20013-7012, U.S.A \\ urn:Isid:zoobank.org:author:76A42D9B-5EFF-4494-8729-C9DF9915CA5B \\ Corresponding author: Robert R. Kula (Robert.Kula@ars.usda.gov) \\ Academic editor:Stefan Schmidt | Received 18 September 2010| Accepted 21 December 2010 | Published 10 March 2011 \\ urn:lsid:zoobank.org:pub:3E497C03-2FAB-4B34-985F-9D2D06F575FC \\ Citation: Kula RR (2011) Two new brachypterous species of Heterospilus Haliday (Hymenoptera, Braconidae, \\ Doryctinae) from the Nearctic Region. Journal of Hymenoptera Research 21: 53-64. doi: 10.3897/JHR.21.875
}

\begin{abstract}
Two new species, Heterospilus belokobylskiji Kula, sp. n. and Heterospilus vincenti Kula, sp. n., from the Nearctic Region are described and differentiated from all other New World species of Doryctinae that exhibit brachyptery or aptery. They are the first brachypterous species of Heterospilus Haliday known in the New World and increase the total number of brachypterous species in the genus to four worldwide.
\end{abstract}

\section{Keywords}

Apterous, aptery, brachyptery, parasitoid, taxonomy

\section{Introduction}

Of the 1,335 species of Doryctinae listed as valid in Yu et al. (2005), 24 species in 12 genera exhibit brachyptery or aptery. Heterospilus hemipterus (Thomson), with the male brachypterous and known only from the neotype (Fischer 1960), and Nipponecphylus matsumurai Belokobylskij \& Konishi, with males apterous and females macropterous 
(Belokobylskij and Konishi 2001), were not listed as such in Yu et al. (2005). Additionally, Australospathius pedestris Belokobylskij, Iqbal \& Austin (females apterous and males macropterous) and Doryctopsis neozealandicus Belokobylskij, Iqbal \& Austin (both sexes apterous), as well as Echinodoryctes lawrencei Belokobylskij, Iqbal \& Austin and Echinodoryctes tetraspinosus Belokobylskij, Iqbal \& Austin (wings represented by scalelike pads in both sexes) (Belokobylskij et al. 2004, S. Belokobylskij in litt.), were not included in Yu et al. (2005). Oroceguera andersoni Seltmann \& Sharkey, with the female apterous and known only from the holotype, was described recently (Seltmann and Sharkey 2007). Thirteen species in the New World are known to exhibit brachyptery or aptery: Aptenobracon formicoides Marsh, Ecphylopsis costaricensis Marsh, Ecphylus caudatus Ruschka, Ecphylus lepturgi Rohwer, Ecphylus pacificus Marsh, Ecphylus schwarzii (Ashmead), O. andersoni, Pambolidea yuma Ashmead, Psenobolus ficarius Ramirez \& Marsh, Psenobolus parapygmaeus Ramirez \& Marsh, Psenobolus triangularis van Achterberg \& Marsh, Termitobracon emersoni Brues, and Ypsistocerus manni Cushman. Seltmann and Sharkey (2007) provided a key to New World genera with brachypterous or apterous species. They did not include Termitobracon Brues and Ypsistocerus Cushman in the key likely because they consider Ypsistocerinae a subfamily as in Wharton et al. (1997) rather than a tribe of Doryctinae as in Yu et al. (2005), although they did not state that viewpoint.

Heterospilus Haliday, the richest doryctine genus in the New World considering the number of undescribed species (P. Marsh in litt.), is one genus for which brachypterous and apterous species are not known in the New World. However, Heterospilus brachyptera (Jakimavicius), with the female brachypterous and known only from the holotype, and $H$. hemipterus have been reported from the Palearctic Region (Fischer 1960, Jakimavicius 1968, Yu et al. 2005).

The author discovered two new brachypterous species of Doryctinae in the Nearctic Region through a study testing pan trap color preference for selected Hymenoptera. The two species fit Heterospilus sensu Marsh (2002) aside from the wings and malar space length and are described herein.

\section{Materials and methods}

Specimens were collected using blue, red, and white 12 ounce Solo $^{\mathrm{TM}}$ (Urbana, Illinois) party bowls placed in an $-100 \mathrm{~m}$ wide power line right-of-way - two miles east of Prince Frederick, Maryland. The clearing runs roughly north-south and is bordered to the east and west by eastern deciduous forest. The flora within the clearing was not surveyed. Topographically, it contains upland areas primarily with herbaceous plants and lowland areas primarily with woody plants. All traps were placed in upland areas. The bowls were filled with a solution of water and Liqui-Nox (Alconox, Inc., White Plains, New York) detergent; the latter served as a surfactant for the water. Contents of the bowls were collected every other day, and the bowls were refilled with waterdetergent solution at that time. 
Specimens were dehydrated using hexamethyldisilazane (HMDS) as in Heraty and Hawks (1998). They were examined as in Kula (2009), and their placement in Heterospilus was determined through reference to Marsh (2002), Marsh (1997), and Seltmann and Sharkey (2007). Additionally, the following specimens were examined: the holotype and two paratypes of $A$. formicoides in the Smithsonian Institution National Museum of Natural History, Washington, DC (USNM); two paratypes of Ecphylopsis costaricensis borrowed from the Canadian National Collection of Insects, Ottawa, Ontario (CNC); the holotype and two paratypes of Ecphylopsis swezeyi Beardsley borrowed from the Bernice P. Bishop Museum, Honolulu, Hawaii, as well as a nontype specimen determined by C. F. W. Muesebeck (USNM); the holotype and a paratype of Ecphylus lepturgi, as well as nontype specimens determined by P. M. Marsh (USNM); the holotype and 10 paratypes of Ecphylus pacificus, as well as nontype specimens determined by P. M. Marsh (USNM); a paratype of Ecphylus schwarzii and nontype specimens determined by P. M. Marsh (USNM); the holotype of Pa. yuma and nontype specimens determined by P. M. Marsh (USNM); nine paratypes of Ps. ficarius (USNM); and four paratypes of Ps. parapygmaeus and nontype specimens determined by C. van Achterberg (USNM). The specimens were determined as new species using unpublished morphological data for $H$. hemipterus obtained from S. A. Belokobylskij (Zoological Institute of Russian Academy of Sciences, St. Petersburg). Belokobylskij (in prep.) considers $H$. brachyptera conspecific with $H$. hemipterus. Thus, the diagnoses herein include the name $H$. hemipterus only.

Terminology for morphological features and setation largely follows Sharkey and Wharton (1997). Pronotal collar, pronotal groove, and subalar groove are as in Marsh (2002); posterior mesopleural furrow is as in Kula (2003). Terminology for surface sculpture primarily follows Harris (1979), but Sharkey and Wharton (1997) and Marsh (2002) were also consulted. Crenulate is as in Sharkey and Wharton (1997); carinae and areas of the propodeum are as in Marsh (2002).

Measurements were taken with an ocular micrometer as in Wharton (1977) with the following additions and modifications. Tergum 1 (T1) length is the maximum length of T1 in lateral view, and T1 width is the width of the posterior edge of T1 in dorsal view. Thorax length and thorax height are referred to as mesosoma length and mesosoma height, respectively. Mesonotal width is referred to as mesoscutal width. Malar space height is the distance between the ventral margin of the eye and the middle of the ventral margin of the malar space. Maximum length was measured for the penultimate maxillary palpomere and $\mathrm{T} 2+\mathrm{T} 3$ mesally. The exposed portion of the ovipositor was measured ventrally to estimate ovipositor length.

Abbreviations used in diagnoses and descriptions are as in Kula (2009) with the following additions: malar space height $(\mathrm{MSH})$, penultimate maxillary palpomere length (PMPL), and exposed ovipositor length (EOL). Abbreviations for museums and collections follow Evenhuis (2010). The material examined sections are formatted as in Kula (2009).

Habitus images were obtained using a Visionary Digital imaging system. The system consists of an Infinity Optics K2 long distance microscope affixed to a Canon EOS 
40D digital SLR camera. A Dynalite M2000er power pack and Microptics ML1000 light box provided illumination. Image capture software is Visionary Digital's proprietary application with images saved as TIF with the RAW conversion occurring in Adobe Photoshop Lightroom 1.4. Image stacks were montaged with Helicon Focus 4.2.1. Final images were prepared using Adobe Illustrator CS4 and are deposited in Morphbank (image ID numbers 581765, 581772, 581777, and 581782).

\section{Results and discussion}

Heterospilus belokobylskiji Kula, sp. n. and Heterospilus vincenti Kula, sp. n. can be differentiated from other brachypterous or apterous doryctines in the New World (excluding ypsistocerines) using form of the wings (Table 1). Additionally, the scutellar disc is flat in H. belokobylskiji and H. vincenti; it is convex in A. formicoides and conical in Ecphylopsis costaricensis. A tubercle is present at the base of the hind coxa in $H$. belokobylskiji and H. vincenti; it is round at the base in Ecphylopsis costaricensis, Ecphylus caudatus, Ecphylus lepturgi, Ecphylus pacificus, and Ecphylus schwarzii. The propodeal bridge is absent in $H$. belokobylskiji and $H$. vincenti; the metasoma articulates with the mesosoma directly above the metacoxae. The propodeal bridge is present between the metacoxae and petiole in $O$. andersoni; the metasoma articulates with the mesosoma high above the metacoxae resulting in a large gap between those features (cf. cenocoeliine braconids). The femora are not enlarged in $H$. belokobylskiji and $H$. vincenti; all femora are enlarged in Pa. yuma, Ps. ficarius, Ps. parapygmaeus, and Ps. triangularis.

Marsh (2002) noted that Beardsley (1961) illustrated a macropterous female holotype of Ecphylopsis swezeyi, known from Hawaii, with the forewing $2 \mathrm{RS}$ vein absent and suggested it might belong in Heterospilus. Three paratypes of Ecphylopsis swezeyi

Table I. Species of Doryctinae in the New World, excluding ypsistocerines, that exhibit brachyptery or aptery.

\begin{tabular}{l|l|l}
\hline Species & Female wing form & Male wing form \\
\hline Aptenobracon formicoides & apterous & apterous \\
\hline Ecphylopsis costaricensis & scalelike pads & scalelike pads \\
\hline Ecphylus caudatus & apterous, macropterous & apterous, macropterous \\
\hline Ecphylus lepturgi & apterous, macropterous & apterous \\
\hline Ecphylus pacificus & unknown & apterous \\
\hline Ecphylus schwarzii & apterous & apterous \\
\hline Heterospilus belokobylskiji Kula, sp. n. & brachypterous & brachypterous \\
\hline Heterospilus vincenti Kula, sp. $\mathrm{n}$. & brachypterous & brachypterous \\
\hline Oroceguera andersoni & apterous & unknown \\
\hline Pambolidea yuma & apterous, macropterous & apterous \\
\hline Psenobolus ficarius & macropterous & brachypterous \\
\hline Psenobolus parapygmaeus & macropterous & brachypterous \\
\hline Psenobolus triangularis & macropterous & brachypterous \\
\hline
\end{tabular}


have the wings represented by scalelike pads. The author regards the holotype and two brachypterous paratypes examined as conspecific. All of the type specimens of Ecphylopsis swezeyi examined are mounted in such a way that the hind coxa is obscured so that the absence or presence of an anteroventral basal tubercle cannot be discerned. However, the hind coxa of a macropterous nontype female at the USNM lacks a tubercle. Further, the scutellar disc is convex in Ecphylopsis swezeyi (more strongly so in brachypterous specimens) and similar in shape to that of Ecphylopsis costaricensis. Therefore, the author retains Ecphylopsis swezeyi in Ecphylopsis at this time. The discovery of males to discern the absence or presence of the hind wing stigma might clarify the generic placement of Ecphylopsis swezeyi.

\section{Taxonomy}

\section{Heterospilus belokobylskiji sp. n.} urn:lsid:zoobank.org:act:09A27F4E-4564-4FA1-95B2-ED283F49D341

Figs $1-2$

Holotype female. U.S.A., "MARYLAND:Calvert Co. [;] 2 mi E Prince Frederick [;] 38 33'3.83"N 76³3'3.09"W [;] 14.v.-16.v.2007 SEL Hym Unit [;] pan trap, transect6 treatment B" (USNM).

Paratype. 1 ก same data as holotype except $38^{\circ} 32^{\prime} 57.95^{\prime \prime} \mathrm{N} 76^{\circ} 33^{\prime} 1.43^{\prime \prime W}$, transect8 treatment W (USNM).

Diagnosis. The vertex is smooth except a pair of small strigulate areas posterolaterad the lateral ocelli in $H$. belokobylskiji; the vertex is entirely strigate to strigate-coriaceous in $H$. hemipterus, and it is entirely coriaceous in $H$. vincenti. The face is smooth in $H$. belokobylskiji; the face is at least partially strigate in $H$. hemipterus, and it is smooth mesally and coriaceous laterally in $H$. vincenti. The frons is partially strigulate in $\mathrm{H}$. belokobylskiji; the frons is entirely coriaceous in $H$. vincenti. The mesopleuron (excluding subalar groove, precoxal sulcus, and posterior mesopleural furrow) is weakly coriaceous with some areas nearly smooth in $H$. belokobylskiji; the mesopleuron is at least partially strigate in $H$. hemipterus. The hind wing stigma of the male is located slightly basad the middle of the wing in $H$. belokobylskiji; the stigma is located at the wing apex in $H$. vincenti. Transverse grooves are absent on T3 in $H$. belokobylskiji; a crenulate transverse groove is present on T3 in $H$. hemipterus. The head (excluding mouthparts and antenna) is brown in $H$. belokobylskiji; the head is yellow in $H$. vincenti.

Description. Female (Fig. 1).

Body length. $2.28 \mathrm{~mm}$.

Head. HL 0.81× HW, HW 1.09× TW, FW 1.92× FH, EL 1.00× EH, MSH 0.80× EH, F1L $0.85 \times$ F2L, PMPL $0.45 \times$ F1L; antenna broken at eighth flagellomere; mandible with two teeth, tooth closest to labiomaxillary complex shorter than other tooth, setiferous; malar space smooth, setiferous, malar suture absent; clypeus with roughly 



Figures I-2. Lateral habitus images of Heterospilus belokobylskiji, scale bars $=1.00 \mathrm{~mm}$. I Female $\mathbf{2}$ Male.

apical $1 / 2$ setiferous and basal $1 / 2$ glabrous; face smooth, glabrous mesally and setiferous laterally; frons partially strigulate and partially smooth, sculpture strongest in depressions dorsad antennal sockets, glabrous except one to two setae along margin of eye; vertex mostly smooth but with pair of small strigulate areas posterolaterad lateral ocelli, setiferous; ocelli present but small (cf. Heterospilus striatus Muesebeck \& Walkley); gena smooth, setiferous; occiput smooth, glabrous except pair of setae ventrally on both sides of head. 
Mesosoma. ML 2.83× MW, ML 1.97× MH, MW 0.70× MH, SSL 0.50× SSW; pronotal collar without transverse carina, anterior portion rugulose and posterior portion smooth mesally and crenulate laterally, anterior and posterior portions both glabrous except setiferous along anterior margins, pronope absent, lateral portion of pronotum (including pronotal groove) rugose, roughly setiferous along margins and glabrous mesally; notauli complete and meeting posteromesally, bearing a few weak crenulae; mesoscutal midpit absent; mesoscutum (excluding lateral margin and notauli) coriaceous, setiferous along margins and notauli; scutellar sulcus with median longitudinal carina and pair of crenulae adjacent to carina; scutellar disc weakly coriaceous, glabrous except five setae along lateral and posterior margins; propodeum strongly carinate, setiferous, carinae forming hastate areola mesally, sculpture within areola areolate-rugose, mesolaterally with transverse carina dividing propodeum into roughly basal and apical halves, dorsal lateral carinae dividing basal $1 / 2$ into median and lateral areas, median area with weak indication of coriaceous sculpture and lateral area areolate-rugulose, apical 1/2 areolate-rugose; subalar groove crenulate; precoxal sulcus present in roughly anterior $1 / 2$ of mesopleuron and crenulate, posterior $1 / 2$ of mesopleuron without impression but with rugosities extending to mesocoxa; posterior mesopleural furrow crenulate; mesopleuron (excluding subalar groove, precoxal sulcus, and posterior mesopleural furrow) weakly coriaceous with some areas nearly smooth, setiferous except glabrous area dorsomesally roughly between subalar groove and posterior mesopleural furrow to level of episternal scrobe; metapleuron areolate-rugose, setiferous; metacoxa with anteroventral basal tubercle.

Forewing. Brachypterous, extending to posterior margin of T2 (including fringe); hyaline; stigma present anterodistally, posterior margin difficult to differentiate from $\mathrm{R} 1$ vein; with following veins complete and tubular: $\mathrm{C}+\mathrm{SC}+\mathrm{R}, \mathrm{M}+\mathrm{CU}, 1-1 \mathrm{~A}, 1 \mathrm{RS}$, $1 \mathrm{M}$, and $1 \mathrm{CU} ;(\mathrm{RS}+\mathrm{M})$ and $\mathrm{m}$-cu veins complete but nebulous resulting in distinct 1 st discal cell; one wing with $3 \mathrm{RS}$ vein minute but tubular and clearly differentiated from stigma and R1 vein.

Hind wing. Brachypterous, extending to posterior margin of T2 (including fringe); hyaline; basal and subbasal cells enclosed by tubular veins, veins enclosing cells differ in width and degree of sclerotization; $\mathrm{R} 1$ vein tubular; $\mathrm{M}+\mathrm{CU}$ vein shorter than $1 \mathrm{M}$ vein.

Metasoma. T1L 1.15× T1W; subcylindrical; ovipositor with minute teeth ventrally, EOL about 2.23× T2+T3L; ovipositor sheaths setiferous, setae increasing in density anteriorly to posteriorly; T1 costate, dorsal carinae extending posteriorly about $3 / 4$ length of tergum, setiferous, dorsope present; $\mathrm{T} 2$ costate, setiferous; transverse groove between T2+T3 weakly impressed, smooth; T3-T7 smooth, setae forming single transverse row in middle or posterior $1 / 2$ of tergum; T8 smooth, setae in no apparent pattern.

Color. Head (excluding mouthparts and antenna) brown, mouthparts whitish yellow except mandible yellow with teeth brown, scape and pedicel yellow, flagellum yellow proximally transitioning to brown distally; mesosoma orangish brown except pronotum and propleuron yellowish brown; wing venation tan; legs yellow; T1-T2 entirely yellowish brown, T3-T5 mostly brown with posterior edge slightly darker but 
all with some irregular yellow coloration, T6 yellow anteromesally but otherwise yellowish brown, T7 yellowish brown, T8 yellow.

Male (Fig. 2). As in female except:

Body length. $2.04 \mathrm{~mm}$.

Head. HL 0.78× HW, HW 1.06× TW, EL 0.93× EH, MSH 0.73× EH, F1L 0.93× F2L, PMPL 0.38× F1L; antenna with 17 flagellomeres; frons glabrous except a few setae along margin of eye.

Mesosoma. ML 2.03× MH, MW 0.72× MH; pronotal collar with anterior portion coriaceous and posterior portion rugulose, scutellar sulcus with median longitudinal carina and pair of shorter longitudinal carinae adjacent to median carina; propodeum with basal and dorsal lateral carinae distinct, basal median area rugulose, remainder of propodeum areolate-rugose, areola (if present) obscured by surrounding sculpture.

Forewing. Extending nearly to end of T3 (including fringe).

Hind wing. Extending nearly to end of T3 (including fringe); stigma slightly basad middle of wing, subelliptical; basal and subbasal cells enclosed by tubular veins except delimited distally by stigma, basal cell delimited ventrally by $\mathrm{M}+\mathrm{CU}$ vein, $1 \mathrm{M}$ vein absent; R1 vein tubular.

Metasoma. T1-T2 costate-rugose; T2 sculpture extending into transverse groove between T2+T3; T3 smooth except band of carinulae anteromesally.

Color. Mesosoma brownish yellow; T1-T2 entirely brownish yellow, T3 brown with posterior edge slightly darker except yellow anteromesally, T4 brown with posterior edge slightly darker, T5-T6 yellow with posterior edge brown, T7-T8 yellow.

Host. Unknown.

Etymology. This species is named in honor of Dr. Sergey A. Belokobylskij for his contributions to braconid systematics and for providing information on brachypterous and apterous doryctines critical to completion of this article.

\section{Heterospilus vincenti Kula, sp. $\mathrm{n}$.}

urn:lsid:zoobank.org:act:0C6454A6-4090-4032-8C26-EF5A3A587CCE

Figs 3-4

Holotype female. U.S.A., "MARYLAND:Calvert Co. [;] 2 mi E Prince Frederick [;] 38 33'4.19"N 76³3'3.96"W [;] 30.v.-1.vi.2007 SEL Hym Unit [;] pan trap, transect5 treatment B" (USNM).

Paratype. 1 o same data as holotype except 38³3'15.72"N 76³3'8.73"W, 14.v.16.v.2007, transect4 treatment R (USNM).

Diagnosis. Heterospilus vincenti can be differentiated from $H$. belokobylskiji using the diagnosis for $H$. belokobylskiji. The vertex is coriaceous in $H$. vincenti; the vertex is strigate to strigate-coriaceous in $H$. hemipterus. The face is smooth mesally and coriaceous laterally in $H$. vincenti; the face is at least partially strigate in $H$. hemipterus. The frons is coriaceous in $H$. vincenti; the frons is strigate $H$. hemipterus. Transverse grooves are absent on $\mathrm{T} 3$ in $H$. vincenti; a crenulate transverse groove is present on $\mathrm{T} 3$ in $H$. 

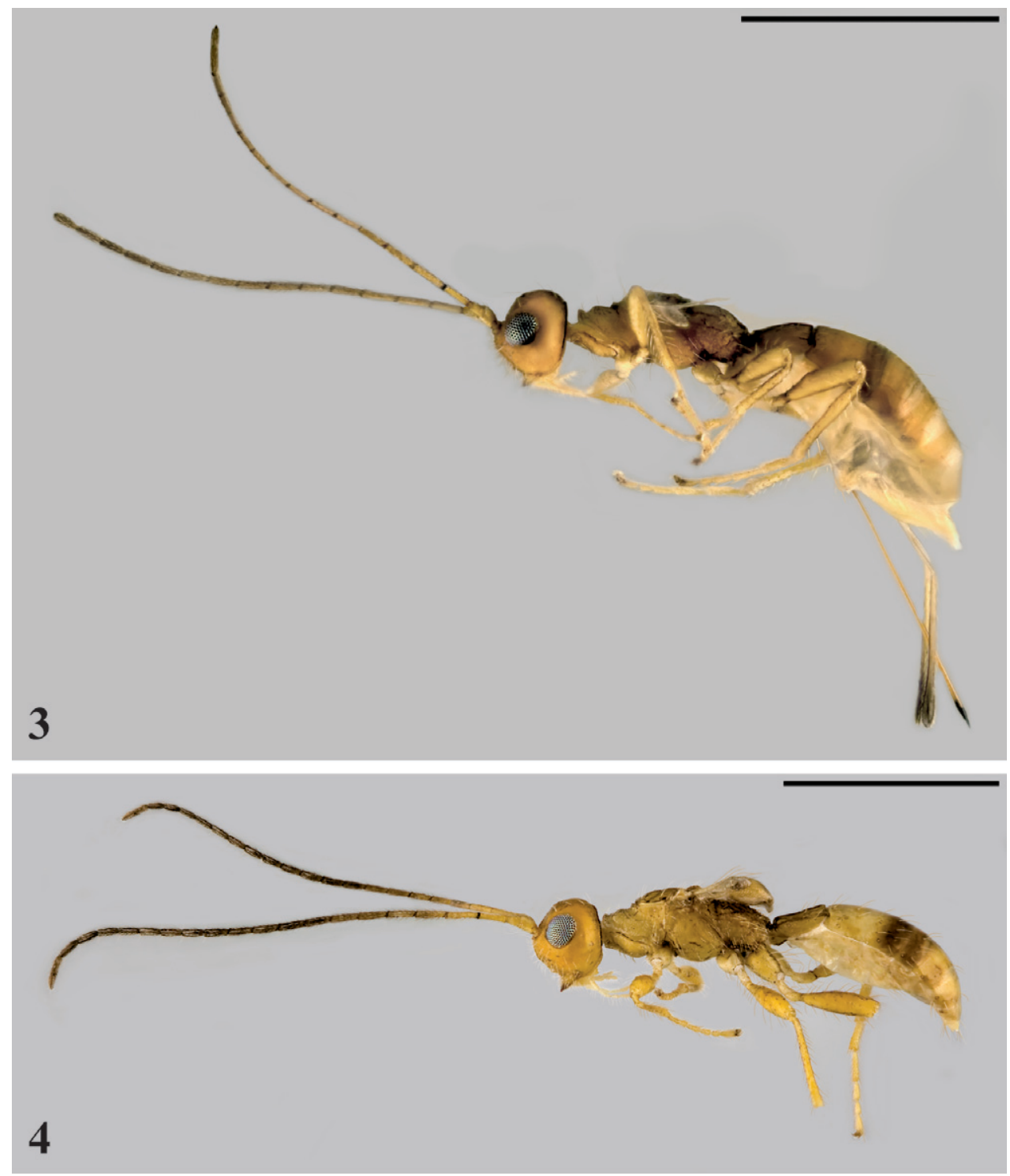

Figures 3-4. Lateral habitus images of Heterospilus vincenti, scale bars = $1.00 \mathrm{~mm}$. 3 Female 4 Male.

hemipterus. The head (excluding mouthparts and antenna) is yellow in $H$. vincenti; the head is dark reddish brown except yellowish brown along eye and ventrally in $H$. hemipterus.

Description. Female (Fig. 3).

Body length. $2.36 \mathrm{~mm}$.

Head. HL 0.77× HW, HW 1.09× TW, FW 1.83× FH, EL 1.00× EH, MSH 1.00× EH, F1L 0.93× F2L, PMPL 0.31× F1L; antenna with 17 flagellomeres; mandible with two teeth, tooth closest to labiomaxillary complex shorter than other tooth, setiferous; 
malar space coriaceous, setiferous, malar suture absent; clypeus with roughly apical $1 / 2$ setiferous and basal 1/2 glabrous; face smooth mesally and coriaceous laterally, glabrous mesally and setiferous laterally; frons coriaceous, glabrous except a few setae along margin of eye; vertex coriaceous, setiferous; ocelli present but small (cf. H. stria$t u s)$; gena coriaceous, setiferous; occiput smooth, glabrous except pair of setae ventrally on both sides of head.

Mesosoma. ML 3.58× MW, ML 2.27× MH, MW 0.63× MH, SSL 0.57× SSW; pronotal collar with transverse carina, anterior portion smooth and posterior portion rugose, anterior and posterior portions both glabrous except setiferous along anterior margins, pronope absent, lateral portion of pronotum (including pronotal groove) rugose except small coriaceous area dorsally, roughly setiferous along ventral and posterior margins but otherwise glabrous; notauli complete to transscutal articulation and separated by carina posteromesally, more strongly impressed anteriorly than posteriorly, bearing a few weak crenulae; mesoscutal midpit absent; mesoscutum (excluding lateral margin and notauli) coriaceous, setiferous along margins and notauli; scutellar sulcus with median longitudinal carina; scutellar disc coriaceous, glabrous except pair of setae laterally; propodeum strongly sculptured, setiferous, with basal and dorsal lateral carinae distinct, basal median area coriaceous, basal lateral area rugose, remainder of propodeum areolate-rugose, areola absent; subalar groove crenulate; precoxal sulcus complete to mesocoxa, more strongly impressed anteriorly than posteriorly, transitioning from crenulate anteriorly to rugose posteriorly; posterior mesopleural furrow crenulate; mesopleuron (excluding subalar groove, precoxal sulcus, and posterior mesopleural furrow) coriaceous, setiferous with setae largely confined to margins, subalar groove, and precoxal sulcus; metapleuron areolate-rugose, setiferous; metacoxa with anteroventral basal tubercle.

Forewing. Brachypterous, extending to end of mesosoma (including fringe); hyaline; stigma absent; venation limited to tubular vein along anterior margin complete to wing apex and vein along posterior margin transitioning from nebulous proximally to tubular distally and bending anteriorly near wing apex to intersect vein along anterior margin.

Hind wing. Brachypterous, extending to end of mesosoma (including fringe); hyaline; basal cell distinct but open, $\mathrm{SC}+\mathrm{R}$ vein spectral distally; subbasal cell enclosed by tubular veins; $\mathrm{SC}+\mathrm{R}$ vein and $1 \mathrm{M}$ vein converge distally to form thickening roughly width of two veins.

Metasoma. T1L 1.14× T1W; subcylindrical; ovipositor with minute teeth ventrally, EOL about 3.28× T2+T3L; ovipositor sheaths setiferous, setae increasing in density anteriorly to posteriorly; T1 costate-rugose, dorsal carinae blending with ground sculpture posteriorly, setiferous, dorsope present; T2 carinate-rugulose, setiferous; transverse groove between T2+T3 absent, T2 and T3 indicated by inconspicuous break in sculpture; T3 carinulate in roughly anterior $1 / 2$, smooth in roughly posterior $1 / 2$, setiferous with most setae forming transverse row in middle of tergum; T4-T8 smooth, setae forming single transverse row in middle or posterior $1 / 2$ of tergum.

Color. Head (excluding mouthparts and antenna) yellow, mouthparts whitish yellow except mandible yellow with teeth brown, scape and pedicel yellow, flagellum yellow proximally transitioning to brown distally; mesosoma yellow with pronotum 
and propleuron slightly lighter; wing venation and legs yellow; T1-T2 entirely yellow, T3-T4 yellow with posterior edge brownish yellow, T5-T8 entirely yellow.

Male (Fig. 4). As in female except:

Body length. $2.38 \mathrm{~mm}$.

Head. HL 0.80× HW, HW 1.11× TW, FW 1.92× FH, EL 0.94× EH, MSH 0.94× EH, F1L 0.88× F2L, PMPL 0.29× F1L; antenna with 20 flagellomeres; gena weakly coriaceous, sculpture barely discernable in some areas; occiput glabrous except a few setae ventrally on both sides of head.

Mesosoma. ML 3.48× MW, ML 2.29× MH, MW 0.66× MH; pronotal collar without transverse carina, anterior portion coriaceous-rugulose and posterior portion rugulose; notauli weakly impressed but complete and meeting posteromesally, bearing a few rugosities; scutellar sulcus with pair of crenulae; scutellar disc bearing three setae; propodeum largely obscured by hind wings but strongly sculptured, basal carina distinct, outer-most dorsal lateral carina indistinct, inner-most dorsal lateral carina (if present) obscured by hind wings, visible portion of basal median area coriaceous, remaining visible portions areolate-rugose, areola (if present) obscured by hind wings.

Forewing: Additional tubular vein located above vein along posterior margin, additional vein arising at base of wing and terminating into vein along posterior margin roughly at its midpoint.

Hind wing: Base of wing membranous with minute veins along anterior and posterior margins; apex of wing with stigmalike swelling bearing flap of wing membrane at distal end of swelling.

Metasoma: T1L 1.26× T1W; T1 carinate-rugose; T2 carinulate-rugose; transverse groove between T2+T3 weakly impressed, T2 and T3 also indicated by inconspicuous break in sculpture; T3 carinulate-rugose in roughly anterior $1 / 2$, smooth in roughly posterior $1 / 2$; T4 with a few crenulae anteriorly but otherwise smooth.

Color: T3 roughly anterior $1 / 3$ yellow and posterior $2 / 3$ brown, T4 yellow anteriorly and brown posteriorly (partially retracted under T3).

Host. Unknown.

Etymology. This species is named for the author's son, Vincent Marion Kula.

\section{Acknowledgments}

I thank Erin Kolski (private contractor; Bowie, Maryland) for sorting pan trap samples and dehydrating, mounting, and labeling specimens. I also thank Matthew Kweskin (formerly Systematic Entomology Laboratory [SEL]) for mounting and labeling specimens. Sergey A. Belokobylskij (Zoological Institute of Russian Academy of Sciences, St. Petersburg) graciously provided information, including unpublished data, for brachypterous and apterous doryctines. I am grateful to Taina Litwak (SEL) for capturing and digitally enhancing the lateral habitus images. Michael G. Pogue (SEL), Thomas J. Henry (SEL), and Paul M. Marsh (Kansas State University) kindly reviewed a presubmission version of the manuscript. 


\section{References}

Beardsley JW (1961) A review of the Hawaiian Braconidae (Hymenoptera). Proceedings of the Hawaiian Entomological Society 17: 333-366.

Belokobylskij SA, Konishi K (2001) New genera of Doryctinae from Japan. Entomological Science 4: 129-138.

Belokobylskij SA, Muhammad I, Austin AD (2004) Systematics, distribution and diversity of the Australasian doryctine wasps (Hymenoptera, Braconidae, Doryctinae). Records of the South Australian Museum Monograph Series 8: 1-150.

Fischer M (1960) Revision der paläarktischen Arten der Gattung Heterospilus Haliday (Hymenoptera, Braconidae). Polskie Pismo Entomologiczne 30: 33-64.

Harris RA (1979) A glossary of surface sculpturing. Occasional Papers in Entomology 28: 1-31. Heraty JM, Hawks D (1998) Hexamethyldisilazane: chemical alternative for drying insects. Entomological News 109: 369-374.

Jakimavicius A (1968) A new genus and species of Braconidae (Hymenoptera) from Lithuania. Entomologicheskoye Obozrenie 47: 902-904.

Kula RR (2003) Morphological variation in Opius Wesmael (Hymenoptera: Braconidae) with an emphasis on Nearctic species in the subgenus Gastrosema Fischer. Journal of Hymenoptera Research 12: 278-302.

Kula RR (2009) Review of the New World species of Coiba Marsh (Hymenoptera: Braconidae: Doryctinae), including descriptions of two new species, new distribution records, and a key to species. Proceedings of the Entomological Society of Washington 111: 183-198.

Marsh PM (1997) Subfamily Doryctinae. In: Wharton RA, Marsh PM, Sharkey MJ (Eds) Manual of the New World Genera of the Family Braconidae (Hymenoptera). Special Publication No. 1. International Society of Hymenopterists, Washington, DC, 206-233.

Marsh PM (2002) The Doryctinae of Costa Rica (excluding the genus Heterospilus). Memoirs of the American Entomological Institute 70: 1-319.

Seltmann K, Sharkey M (2007) A new genus and species of apterous Doryctinae (Hymenoptera: Braconidae) from Costa Rica. Zootaxa 1415: 17-24.

Sharkey MJ, Wharton RA (1997) Morphology and terminology, In: Wharton RA, Marsh PM, Sharkey MJ (Eds) Manual of the New World Genera of the Family Braconidae (Hymenoptera). Special Publication No. 1. International Society of Hymenopterists, Washington, DC, 19-37.

Wharton RA (1977) New World Aphaereta species (Hymenoptera: Braconidae: Alysiinae), with a discussion of terminology used in the tribe Alysiini. Annals of the Entomological Society of America 70: 782-803.

Wharton RA, Marsh PM, Sharkey MJ (1997) Manual of the New World Genera of the Family Braconidae (Hymenoptera). Special Publication No. 1. International Society of Hymenopterists, Washington, DC, 439 pp.

Yu DS, van Achterberg K, Horstmann K (2005) World Ichneumonoidea 2004. Taxonomy, Biology, Morphology and Distribution. DVD/CD. Taxapad, Vancouver. 